11

\title{
Абляция и фрагментация золотых наночастиц под действием интенсивного лазерного облучения в спектральных областях дипольного и квадрупольного плазмонных резонансов
}

\author{
(С) П.В. Гладских, И.А. Гладских, М.А. Баранов, Т.А. Вартанян
}

Университет ИТМО, 197101 Санкт-Петербург, Россия

ฯ e-mail: tigran.vartanyan@mail.ru

Поступила в редакцию 11.02.2020 г.

В окончательной редакции 11.02.2020 г.

Принята к публикации 17.02.2020 г.

\begin{abstract}
Предложены методы вакуумного напыления и последующей термической обработки тонких пленок золота, позволяющие получать как предельно малые наночастицы золота со спектрально узкими дипольными плазмонными резонансами, так и более крупные наночастицы, поддерживающие квадрупольные колебания. Экспериментально исследовано влияние мощного лазерного излучения как на малые, так и на крупные металлические наночастицы в областях дипольного и квадрупольного резонансов соответственно. Мощное лазерное облучение приводит к абляции малых частиц, в то время как крупные частицы при облучении распадаются на частицы меньшего размера.
\end{abstract}

Ключевые слова: локализованный плазмонный резонанс, золотые наночастицы, лазерная абляция, фрагментация наночастиц, квадрупольный резонанс.

DOI: $10.21883 / \mathrm{OS} .2020 .06 .49400 .38-20$

\section{Введение}

Коллективное возбуждение электронов проводимости в металлических наночастицах, возникающее при их взаимодействии со светом, - локализованный поверхностный плазмонный резонанс (LSPR) - не только активно исследуется учеными, но и находит многочисленные применения в различных сферах от оптоэлектроники до медицины. Это связано с тем, что в резонансе металлические наночастицы имеют большое сечение поглощения, значительно превышающее их геометрическое сечение, а электромагнитное поле вблизи наночастицы многократно усиливается по сравнению с полем возбуждающего излучения. Это позволяет получить измеримый оптический отклик даже от крайне малого количества исследуемого вещества, обладающего относительно слабыми оптическими переходами. Примерами применения локализованного плазмонного резонанса могут служить эффекты гигантского комбинационного рассеяния света (SERS) [1], усиленной металлом флуоресценции (MEF) [2], поверхностно усиленного поглощения в ближней инфракрасной области (SENIRA) [3] и другие [4]. Разнообразие применений плазмонных эффектов обусловлено возможностью изменения положения плазмонного резонанса в соответствии с поставленной задачей в широком диапазоне оптических частот путем выбора материала частицы, ее размера, формы и диэлектрического окружения. В связи с этим одним из главных направлений исследований в плазмонике является развитие методов создания плазмонных наноструктур.
Наиболее простыми остаются методы самоорганизации металлических наноструктур на поверхности подложек при вакуумном напылении (PVD) [5]. Процессы, происходящие при росте металлических наноструктур при вакуумном напылении, достаточно хорошо изучены, что позволяет получать простейшие структуры с необходимыми свойствами [6,7]. В то же время методы, основанные на самоорганизации наноструктур, проигрывают химическим и литографическим методикам в гибкости и точности определения параметров металлических наночастиц и наноструктур на их основе. В связи с этим особое значение приобретают методики постобработки образцов, полученных в результате самоорганизации. Это позволяет уменьшать разброс частиц по размерам и более точно подстраивать их оптические свойства. К таким методам можно отнести температурную и лазерную обработку $[8,9]$. Отличительной особенностью лазерной обработки является селективность воздействия лазерного излучения на ансамбли металлических наночастиц с широким распределением по форме и размеру. При достаточной энергии лазерного излучения происходит выжигание постоянных спектральных провалов на длине волны возбуждения вследствие изменения формы наночастиц, у которых плазмонный резонанс располагается вблизи длины волны возбуждения [1013]. При интенсивном лазерном воздействии происходит фрагментация металлических наночастиц [14,15], которая объясняется в зависимости от условий эксперимента либо эффектами абляции, либо кулоновским взрывом сильно ионизированных частиц [16]. 
В настоящей работе рассматривается резонансное взаимодействие мощного лазерного излучения с наночастицами золота при облучении в области дипольного и квадрупольного плазмонных резонансов.

\section{Методы получения и исследования образцов}

В работе исследовались золотые наноструктуры двух типов: 1) диэлектрические пленки, содержащие в себе золотые включения в виде малоатомных кластеров и наночастиц, и 2) островковые пленки золота, покрытые слоем диэлектрического материала.

В первом случае образцы были получены методом физического осаждения паров золота (99.99\%) в вакууме с одновременным напылением $\mathrm{SiO}_{2}(99.99 \%)$ на поверхность кварцевых подложек. Напыление производилось в вакуумной установке PVD-75 (Kurt J. Lesker). Золото напылялось из резистивно нагреваемой вольфрамовой лодочки. $\mathrm{SiO}_{2}$ напылялся с помощью электронно-лучевого испарителя. Напыление осуществлялось на подложку при комнатной температуре. Скорость напыления и количество осажденного материала контролировались кварцевым датчиком толщины. Изменение отношения скоростей напыления золота и $\mathrm{SiO}_{2}$ позволяло варьировать концентрацию золота в пленке. В результате были получены образцы в виде тонких пленок $\mathrm{SiO}_{2}$ с содержанием золота $1.1,1.6,3.2$ и $6.3 \%$. Толщина пленок не превышала $250 \mathrm{~nm}$.

Во втором типе образцов напыление происходило поэтапно. Сначала напылялась островковая пленка золота на поверхность сапфировой подложки, разогретой до температуры $500^{\circ} \mathrm{C}$. Затем на нее напылялась пленка $\mathrm{Al}_{2} \mathrm{O}_{3}$ толщиной $50 \mathrm{~nm}$. Была получена серия образцов с эквивалентными толщинами золота 5, 15, $30 \mathrm{~nm}$ (под эквивалентной или массовой толщиной островковой пленки понимается толщина сплошной пленки, в которой содержится такое же количество вещества на единицу площади образца, как и в реальной островковой пленке).

Образцы были исследованы с помощью стандартных методов абсорбционной оптической спектроскопии. Спектры оптической плотности были получены с помощью спектрофотометра СФ-56 (ЛОМО) в интервале длин волн 200-1100 nm.

Изменение морфологии образцов и их оптических свойств осуществлялось с помощью термической и лазерной обработки. Нагрев происходил в муфельной печи на воздухе при максимально выставленной температуре $1050^{\circ} \mathrm{C}$. Так как металлические частицы во всех образцах либо находились непосредственно в диэлектрической пленке, либо были покрыты сплошной диэлектрической пленкой, контакт металлических наночастиц с воздушной атмосферой был исключен.

Для лазерной обработки был применен импульсный $\mathrm{Nd}$ : YAG-лазер. Использовалась вторая гармоника излучения с длиной волны $\lambda=532 \mathrm{~nm}$. Длительность одного
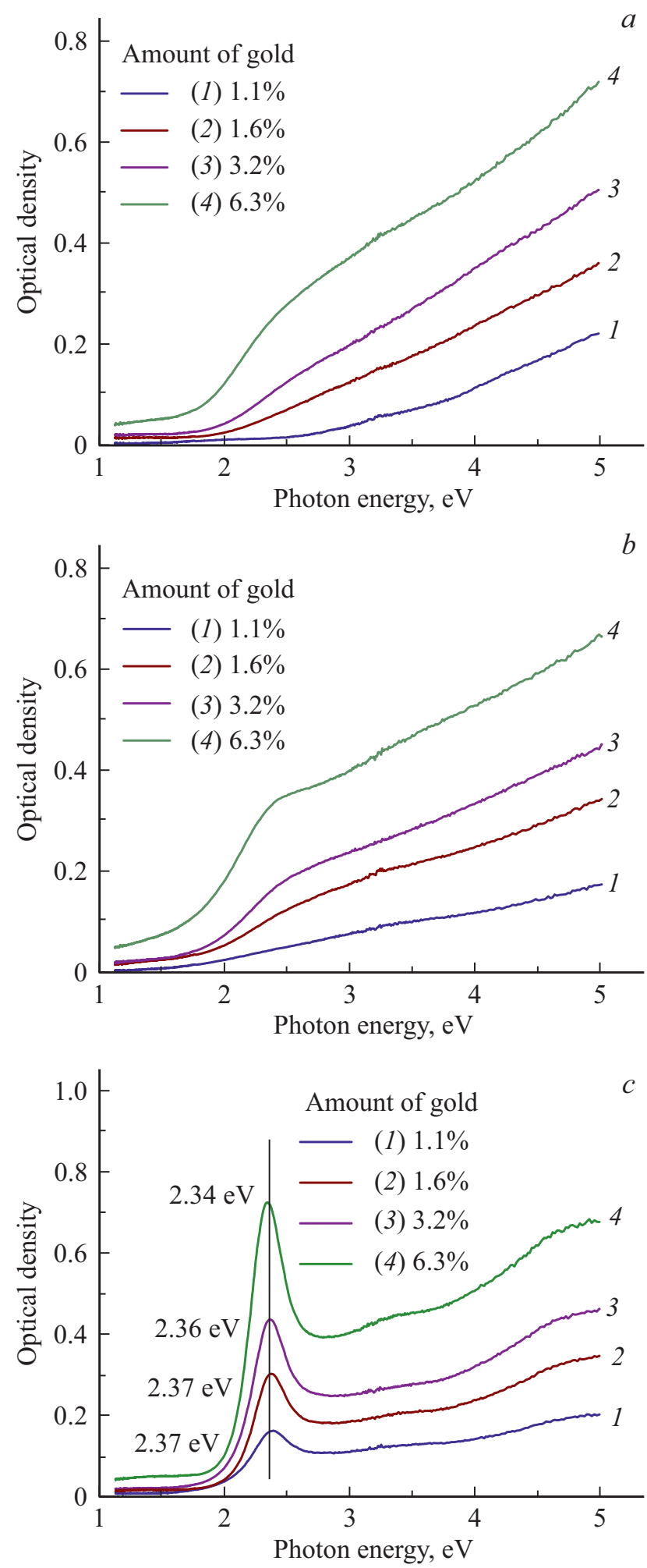

Рис. 1. Спектры оптической плотности тонких пленок $\mathrm{SiO}_{2}$ c различной концентрацией золота непосредственно после напыления $(a)$ и после термического отжига при $500^{\circ} \mathrm{C}(b)$ и при $1050^{\circ} \mathrm{C}(c)$.

импульса составляла $\tau=10 \mathrm{~ns}$; максимальная энергия импульса $-E_{\max }=250 \mathrm{~mJ}$; площадь пятна излучения - 
$0.5 \mathrm{~cm}^{2}$. На каждое облучение образца приходилось 100 импульсов.

Спектры оптической плотности измерялись на каждом этапе исследования.

\section{Результаты исследования}

Были получены серии образцов с содержанием золота $1.1,1.6,3.2$ и $6.3 \%$. На рис. 1 показаны спектры поглощения образцов с различным количеством золота непосредственно после осаждения (рис. $1, a$ ), после термического отжига при $500^{\circ} \mathrm{C}$ в течение $1 \mathrm{~h}$ (рис. $\left.1, b\right)$ и при $1050^{\circ} \mathrm{C}$ в течение $1 \mathrm{~h}$ (рис. 1,c) в муфельной печи. Поглощение образцов непосредственно после осаждения монотонно возрастает при движении от видимого диапазона к ультрафиолетовой (УФ) части спектра. С увеличением количества золота в пленке помимо возрастания величины оптической плотности наблюдается длинноволновый сдвиг края поглощения. Отсутствие четко выраженной плазмонной полосы поглощения свидетельствует об образовании очень малых золотых кластеров, в которых коллективные возбуждения электронов отсутствуют [17].

Термический отжиг при $500^{\circ} \mathrm{C}$ приводит к увеличению оптической плотности в длинноволновой области и уменьшению в УФ области. Плазмонный резонанс наночастиц золота при $2-2.5 \mathrm{eV}$ наблюдался в отожженных образцах с концентрацией золота более $3.2 \%$. После отжига при $1050^{\circ} \mathrm{C}$ узкий плазмонный резонанс в интервале $2.3-2.4 \mathrm{eV}$ отчетливо наблюдается у всех исследованных образцов, причем с увеличением концентрации золота наблюдается длинноволновый сдвиг плазмонного резонанса наночастиц. Появление плазмонной полосы поглощения после отжига естественно связать с термической активацией диффузии атомов золота, приводящей к росту больших кластеров за счет меньших и формированию золотых наночастиц достаточно большого размера для поддержания плазмонных колебаний.

Результаты исследования лазерного воздействия на образец с концентрацией золота 6.3\% представлены на рис. 2. Длина волны лазерного излучения была очень близка к максимуму плазмонного резонанса. Импульсы с плотностью энергии, меньшей $150 \mathrm{~mJ} \cdot \mathrm{cm}^{-2}$, практически не вызывали изменения оптических свойств образца. Более мощные импульсы приводили к уменьшению оптической плотности в максимуме плазмонного резонанса и к его небольшому длинноволновому сдвигу. Наибольшее изменение было вызвано импульсами с энергией $500 \mathrm{~mJ} \cdot \mathrm{cm}^{-2}$, однако значительное уменьшение оптической плотности (рис. 2, $a$ ) и визуальное обследование состояния поверхности образца показали, что это связано с абляцией пленки.

Изменение спектров экстинкции данного образца лучше всего видно на разностном спектре, полученном вычитанием спектра экстинкции необлученной пленки из спектров экстинкции, измеренных после облучения.
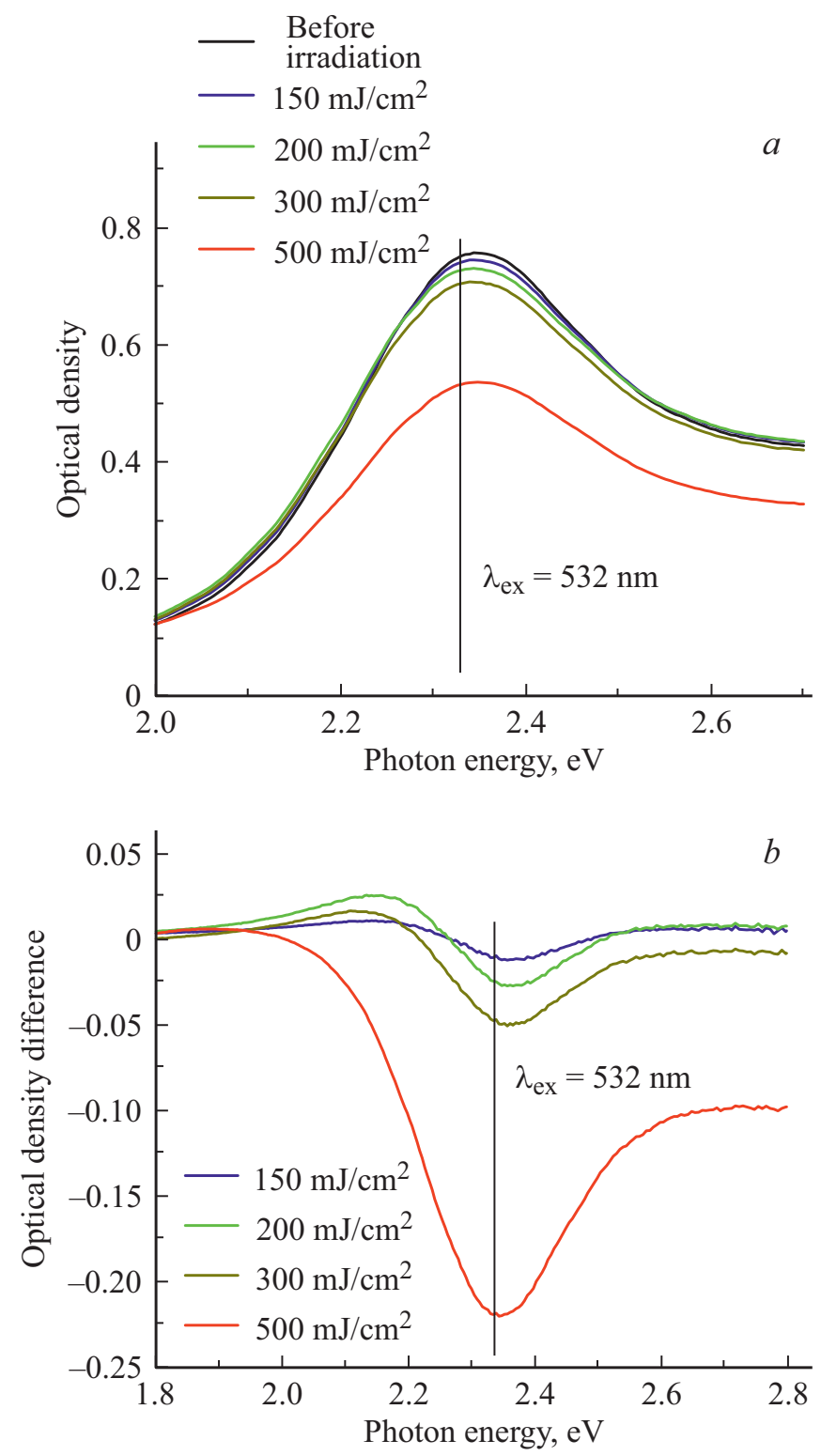

Рис. 2. Спектры оптической плотности $(a)$ и разностные спектры $(b)$ пленки $\mathrm{SiO}_{2}$, содержащей 6.3\% золота, до и после лазерного облучения.

На длине волны лазерного излучения наблюдается спектральный провал. Вместе с этим в длинноволновой области спектра оптическая плотность несколько возрастает (за исключением последнего спектра). Поскольку увеличение размера наночастиц приводит к длинноволновому сдвигу дипольного плазмонного резонанса, изменение спектров оптической плотности при воздействии резонансного лазерного излучения на образец можно объяснить увеличением среднего размера частиц.

У образцов второго типа, несмотря на то, что золото напылялось на горячую подложку, плазмонный резонанс наночастиц сильно уширен из-за широкого распределения частиц по размеру и форме (рис. 3,a). Для пленки с эквивалентной толщиной $15 \mathrm{~nm}$ наблюда- 

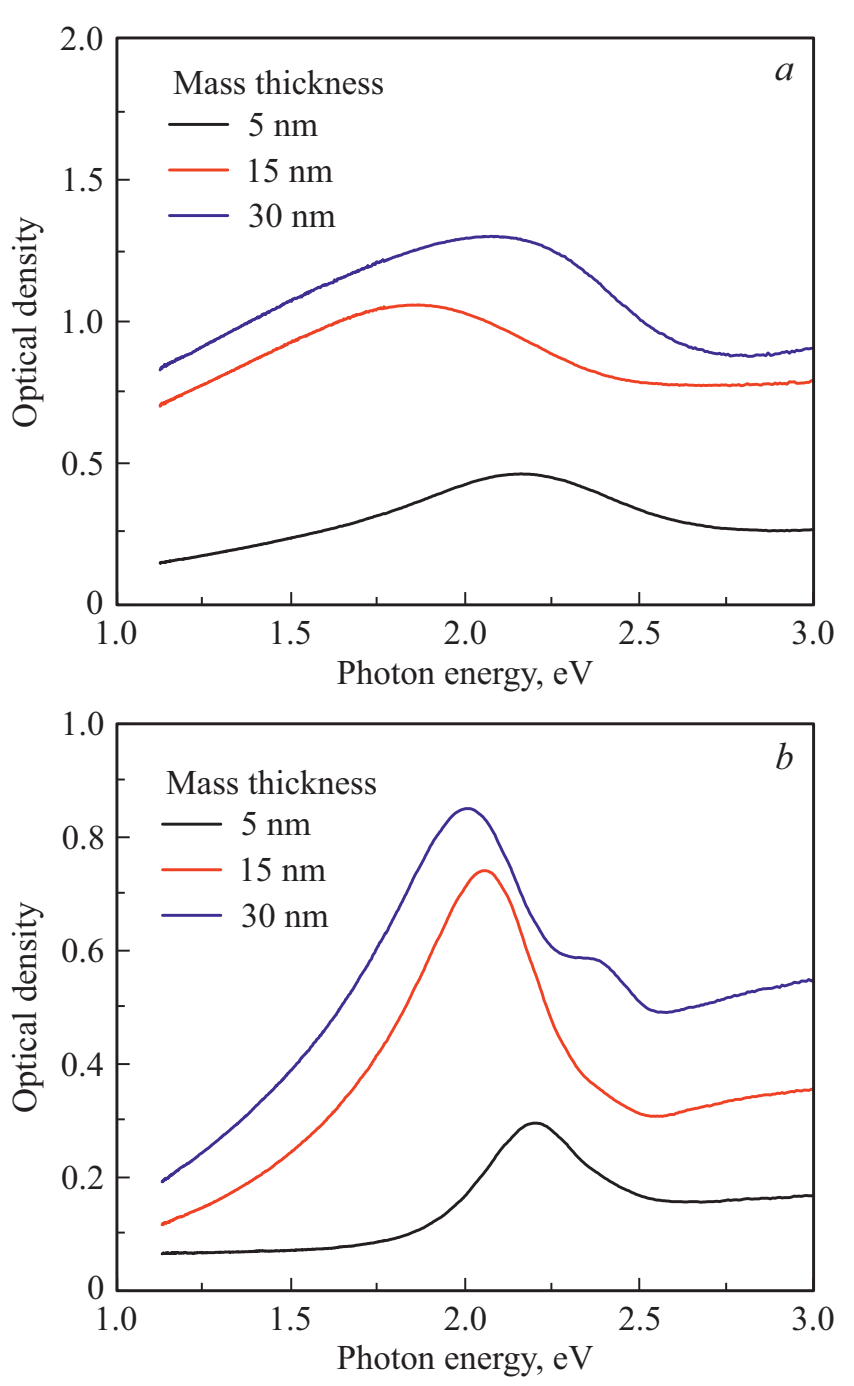

Рис. 3. Спектры оптической плотности пленок золота различной толщины после напыления $(a)$ и термического отжига $(b)$.

ется длинноволновый сдвиг плазмонного резонанса по отношению к пленке с эквивалентной толщиной $5 \mathrm{~nm}$, связанный с увеличением среднего размера частиц. Для пленки толщиной $30 \mathrm{~nm}$ спектр оптической плотности сместился в коротковолновую область по сравнению с пленкой толщиной $15 \mathrm{~nm}$, что может быть обусловлено увеличением коэффициента отражения света от золотой пленки, морфология которой при увеличении покрытия подложки металлом становиться близкой к сплошной. После отжига плазмонная полоса поглощения заметно сужается и смещается в коротковолновую область спектра (рис. 3, b). Наблюдается красный сдвиг плазмонного резонанса с увеличением количества напыленного материала. Помимо дипольного резонанса у пленки толщиной $30 \mathrm{~nm}$ наблюдается также квадрупольный резонанс, эффективность возбуждения которого заметно возрастает в частицах диаметром более $150 \mathrm{~nm}$ [18].

Результаты исследования влияния лазерного излучения на пленку толщиной $30 \mathrm{~nm}$ представлены на рис. 4.
В данном случае излучение резонансно квадрупольной моде плазмонного резонанса. Несмотря на то, что облучение происходило в области квадрупольного резонанса, основные изменения спектров оптической плотности наблюдаются в области дипольного резонанса, причем при значительно меньших энергиях импульса, чем при облучении непосредственно в области дипольного резонанса. После облучения пленки лазером с плотностью энергии импульса $60 \mathrm{~mJ} \cdot \mathrm{cm}^{-2}$ дипольный резонанс сужается и смещается в коротковолновую область. Это связано с изменением формы наночастиц золота, наблюдавшемся также и при термическом отжиге.

При плотности энергии импульсов, превышающей $160 \mathrm{~mJ} \cdot \mathrm{cm}^{-2}$, максимум плазмонного резонанса продолжает смещаться в коротковолновую область спектра, но плазмонная полоса поглощения начинает уширяться появляется длинноволновое плечо, которое возрастает с увеличением энергии импульса.
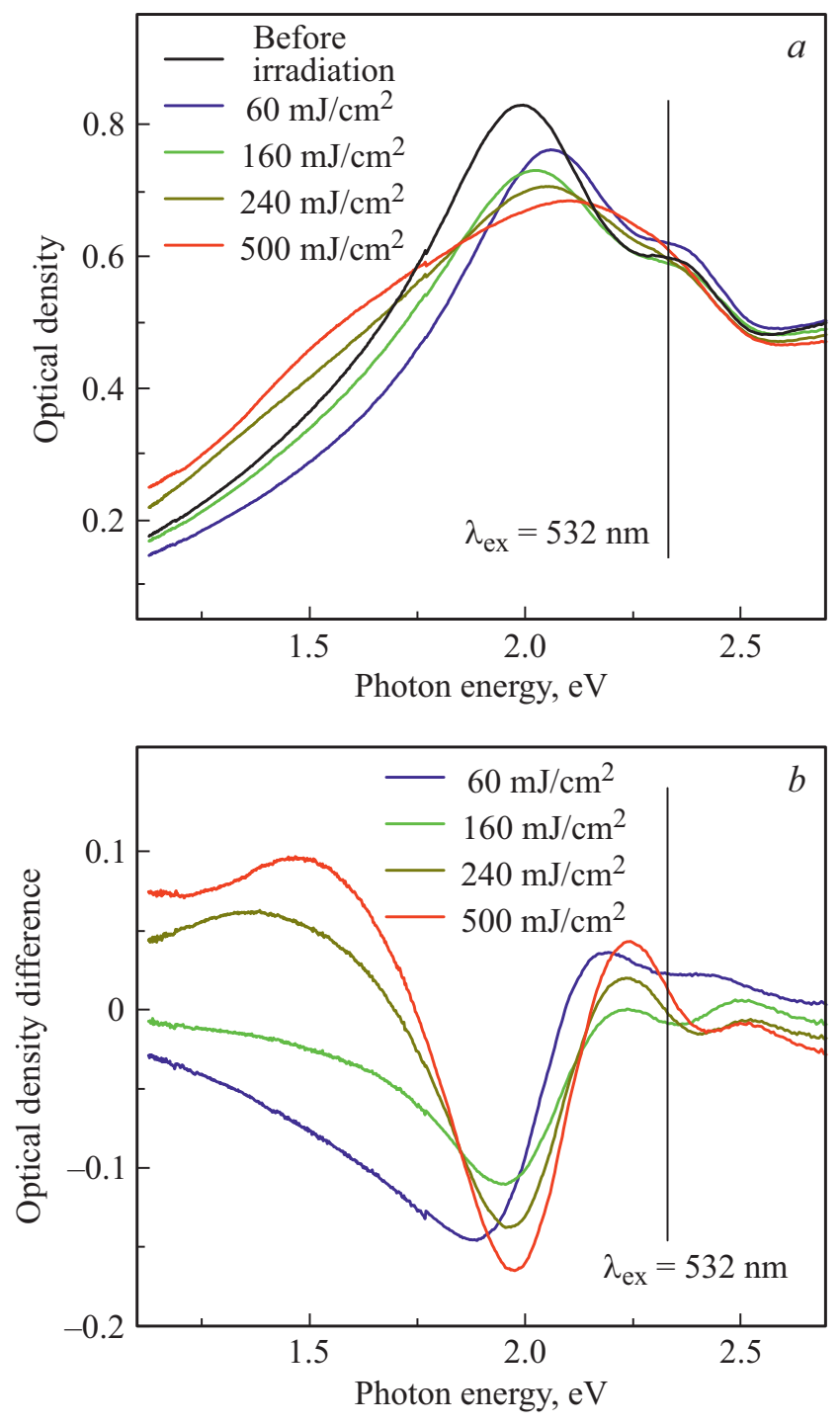

Рис. 4. Спектры оптической плотности $(a)$ и разностные спектры $(b)$ пленки золота толщиной $30 \mathrm{~nm}$ при лазерном облучении. 

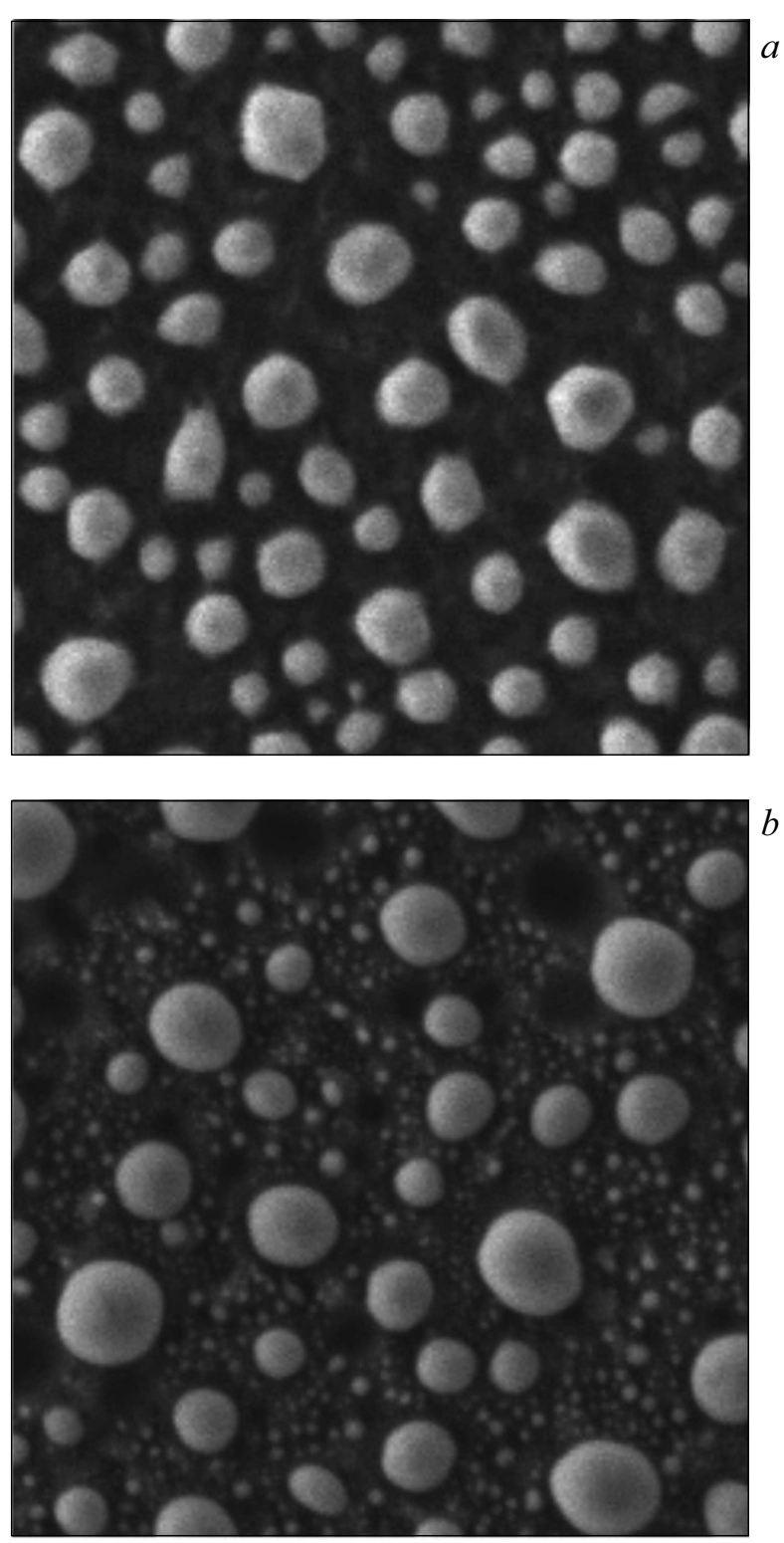

Рис. 5. СЭМ изображения $(2 \times 2 \mu \mathrm{m})$ пленки золота толщиной $30 \mathrm{~nm}$ после отжига при температуре $1050^{\circ} \mathrm{C}$ в течение $60 \min (a)$ и после облучения 100 импульсами лазерного излучения на длине волны $532 \mathrm{~nm}$ с энергией $500 \mathrm{~mJ} \cdot \mathrm{cm}^{-2}(b)$.

Аналогично изменения спектров при лазерном воздействии также представлены на разностном спектре (рис. $4, b)$. Под действием лазерного облучения образуются два спектральных провала, расположенные в областях как дипольного, так и квадрупольного резонансов. При больших энергиях лазерных импульсов происходит увеличение оптической плотности в длинноволновой области спектра и в промежуточной области между дипольным и квадрупольным резонансами.

Изображения золотых пленок, полученные в сканирующем электронном микроскопе (SEM), показывают (рис. 5), что в результате лазерной обработки крупные наночастицы подверглись фрагментации с образованием меньших по размеру близкорасположенных наночастиц. С этим связан сдвиг плазмонного резонанса в коротковолновую область спектра. Увеличение длинноволнового плеча вызвано взаимодействием близкорасположенных частиц [19].

\section{Заключение}

В работе показаны результаты влияния термической и лазерной обработки на пленки, содержащие как золотые кластеры, так и наночастицы. Продемонстрирована возможность получения как кластеров, состоящих из небольшого числа атомов, так и более крупных образований - наночастиц, поддерживающих дипольные и даже квадрупольные плазмонные колебания.

В случае диэлектрических пленок, содержащих золотые кластеры, термический отжиг приводит к коалесценции золотых кластеров и образованию более крупных плазмонных частиц с узким резонансом в районе $2.35 \mathrm{eV}$. Лазерное излучение незначительно влияет на такие пленки, сдвигая максимум плазмонного резонанса в длинноволновую область спектра, что связано с дальнейшим укрупнением частиц.

Обратная ситуация наблюдается у островковых пленок золота, состоящих из крупных частиц. Отжиг приводит к формированию частиц более правильной формы и сдвигу плазмонного резонанса в коротковолновую область спектра. У островковой пленки золота с эквивалентной толщиной $30 \mathrm{~nm}$ помимо дипольного резонанса в спектре оптической плотности наблюдается также квадрупольный резонанс. Лазерное излучение, действующее в области квадрупольного резонанса, приводит к фрагментации крупных металлических наночастиц с большей эффективностью, чем при лазерном воздействии в области дипольного резонанса.

\section{Финансирование работы}

Работа выполнена при государственной финансовой поддержке ведущих университетов Российской Федерации (субсидия 08-08).

\section{Конфликт интересов}

Авторы заявляют, что у них нет конфликта интересов.

\section{Список литературы}

[1] Maslovski S.I., Simovski C.R. // Nanophotonics. 2019. V. 8. N 3. P. 429. doi 10.1515/nanoph-2018-0190

[2] Jeong Y., Kook Y.M., Lee K., Koh W.G. // Biosensors and Bioelectronics. 2018. V. 111. P. 102. doi 10.1016/j.bios.2018.04.007

[3] Dadadzhanov D.R., Vartanyan T.A., Karabchevsky A. // Optics Express. 2019. V. 27. N 21. P. 29471. doi 10.1364/OE.27.029471 
[4] Lepeshov S., Gorodetsky A., Krasnok A., Toropov N., Vartanyan T.A., Belov P., Alú A., Rafailov E.U. // Scientific Reports. 2018. V. 8. N 1. P. 6624. doi 10.1038/s41598-018-25013-7

[5] Toropov N., Vartanyan T. Comprehensive Nanoscience and Nanotechnology. 2019. P. 61. doi 10.1016/b978-0-12-8035818.00585-3

[6] Gladskikh I.A., Leonov N.B., Przhibel'skil S.G., Vartanyan T.A. // J. Optical Technology. 2014. V. 81. N 5. P. 280. doi 10.1364/JOT.81.000280

[7] Vashchenko E.V., Vartanyan T.A., Hubenthal F. // Plasmonics. 2013. V. 8. P. 1265. doi 10.1007/s11468-013-9544-8

[8] Leonov N.B., Gladskikh I.A., Polishchuk V.A., Vartanyan T.A. // Opt. Spectrosc. 2015. V. 119. N 3. P. 450. doi 10.1134/S0030400X15090179

[9] Toropov N.A., Gladskikh I.A., Parfenov P.S., Vartanyan T.A. // Optical and Quantum Electronics. 2017. V. 49. N 4. P. 154. doi 10.1007/s11082-017-0996-5

[10] Stietz F., Bosbach J., Wenzel T., Vartanyan T., Goldmann A., Träger F. // Phys. Rev. Lett. 2000. V. 84. N 24. P. 5644. doi 10.1103/PhysRevLett.84.5644

[11] Vartanyan T., Bosbach J., Stietz F., Träger F. // Appl. Phys. B. 2001. V. 73. N 4. P. 391. doi 10.1007/s003400100714

[12] Bosbach J., Hendrich C., Vartanyan T., Stietz F., Träger F. // The European Physical J. D. 2001. V. 16. N 1. P. 213. doi $10.1007 / \mathrm{s} 100530170095$

[13] Bosbach J., Hendrich C., Stietz F., Vartanyan T., Träger F. // Phys. Rev. Lett. 2002. V. 89. N 25. P. 257404. doi 10.1103/PhysRevLett.89.257404

[14] Kamat P.V., Flumiani M., Hartland G.V. // J. Phys. Chem. B. 1998. V. 102. N 17. P. 3123. doi 10.1021/jp980009b

[15] González-Rubio G., Guerrero-Martínez A., Liz-Marzán L.M. // Accounts of Chemical Research. 2016. V. 49. N 4. P. 678. doi 10.1021/acs.accounts.6b00041

[16] Gruzdev V.E., Komolov V.L., Przhibel'skið S.G. // J. Optical Technology. 2014. V. 81. N 5. P. 256. doi 10.1364/JOT.81.000256

[17] Wilcoxon J.P., Abrams B.L. // Chemical Society Reviews. 2006. V. 35. N 11. P. 1162. doi 10.1039/b517312b

[18] Shopa M., Kolwas K., Derkachova A., Derkachov G. // Opto-Electronics Review. 2010. V. 18. N 4. P. 421. doi 10.2478/s11772-010-0047-2

[19] Jiang M.M., Chen H.Y., Li B.H., Liu K.W., Shan C.X., Shen D.Z. // J. Materials Chemistry C. 2014. V. 2. N 1. P. 56. doi $10.1039 / \mathrm{c} 3 \mathrm{tc} 31910 \mathrm{e}$ 